\begin{tabular}{|c|c|c|}
\hline 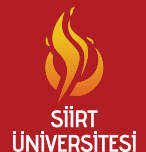 & $\begin{array}{c}\text { Türkiye Tarımsal Araştırmalar Dergisi } \\
\text { dergipark.org.tr/tutad }\end{array}$ & $\begin{array}{l}\text { Turk J Agric Res } \\
\text { 2019, 6(3): 277-284 } \\
\text { ○ TÜTAD } \\
\text { ISSN: 2148-2306 } \\
\text { e-ISSN: 2528-858X }\end{array}$ \\
\hline Bilimin Prüunda & Araştırma Makalesi / Research Article & doi: 10.19159/tutad.590387 \\
\hline
\end{tabular}

\title{
Haplophyllum suaveolens Varyetelerinin Antioksidan Aktivitesi ve Sekonder Metabolitleri Üzerine Farklı Çözücülerin Etkisi
}

\author{
Cennet YAMAN ${ }^{1 *}$, Deniz ULUKUŞ ${ }^{2}$, Osman TUGAY ${ }^{3}$ \\ ${ }^{1}$ Bozok Üniversitesi, Ziraat Fakültesi, Tarla Bitkileri Bölümü, Yozgat, TÜRKIYYE \\ ${ }^{2}$ Selçuk Üniversitesi, Fen Fakültesi, Biyoteknoloji Bölümü, Konya, TÜRKIYE \\ ${ }^{3}$ Selçuk Üniversitesi, Eczacılık Fakültesi, Farmasötik Botanik Anabilim Dalı, Konya, TÜRKIYYE
}

\begin{tabular}{|c|c|}
\hline Geliş Tarihi/Received: 10.07 .2019 & Kabul Tarihi/Accepted: 22.10 .2019 \\
\hline \multicolumn{2}{|l|}{ ORCID ID (Yazar sirasma göre / by author order) } \\
\hline (1Dorcid.org/0000-0002-2364-8171 (Dorcid.org/0000-0002-9 & rcid.org/0000-0003-3980-7648 \\
\hline
\end{tabular}

Öz: Bu çalışmada, Haplophyllum suaveolens varyetelerine ait methanol ve etanol ekstraktlarının toplam biyoaktif içerikleri ile antioksidan aktivite seviyelerinin belirlenmesi amaçlanmıştır. Ekstraksiyon işleminde Haplophyllum suaveolens varyeteleri olan Haplophyllum suaveolens (DC.) G.Don var. suaveolens (HS) ve endemik Haplophyllum suaveolens var. cilicicum (Boiss.) C.C.Townsend (HC) taksonlarının herba kısımları kullanılmıștır. Toplam fenolik içerik Folin-Ciocalteu metotuna göre belirlenmiş ve her bir ekstrakttaki miktarları mg gallik asit eş değer (GAE) $\mathrm{g}^{-1}$ ekstrakt olarak ifade edilmiştir. Ekstraktların toplam fenolik içerikleri 39.54-44.16 mg GAE g-1 ekstrakt arasında değişim göstermiștir. Toplam flavonoid içerikleri ise mg kuersetin eş değer (QE) g-1 ekstrakt olarak ölçülmüş ve 17.30-41.40 mg QE g-1 ekstrakt arasında değişim göstermiştir. Çalışmada, HS ve HC taksonlarının methanol ekstraktları en yüksek 2,2-difenil-1-pikrilhidrazil (DPPH, sırayla $\% 79.76$ ve \% 75.69) ve 2,2'-azinobis (3-etil-bezotiazolin 6 sulfonat) (ABTS, sirayla \% 54.74 ve \% 55.13) radikal kovucu aktiviteleri göstermiştir. Böylece, Haplophyllum suaveolens varyetelerinin güçlü radikal kovucu aktivite sergilediği ve her iki varyete içinde metanol ekstraktların etanol ekstraktlarına göre daha etkili olduğu tespit edilmiştir. Bu çalşma ile Haplophyllum suaveolens varyetelerinin güçlü radikal kovucu aktiviteye sahip olduğu, tıbbi ve ticari kullanım için iyi birer doğal antioksidan kaynağı olabileceği tespit edilmiştir.

Anahtar Kelimeler: Antioksidan aktivitesi, flavonoid, Haplophyllum L., fenolik

\section{Effect of Different Solvents on Antioxidant Activities and Secondery Metabolites of Haplophyllum suaveolens Varieties}

\begin{abstract}
In this study, total bioactive contents and antioxidant activity levels of methanol and ethanol extracts of Haplophyllum suaveolens varieties were determined. Aerial parts of Haplophyllum suaveolens varieties which are Haplophyllum suaveolens (DC.) G. Don var. suaveolens (HS) and endemic Haplophyllum suaveolens var. cilicicum (Boiss.) C.C. Townsend (HC), were used in the extraction process. Total phenolic content was determined according to the FolinCiocalteu method and the amounts in each extract were expressed as mg gallic acid equivalent (GAE) g-1 extract. The total phenolic contents of the extracts varied between 39.54-44.16 $\mathrm{mg} \mathrm{GAE} \mathrm{g}^{-1}$ extract. Total flavonoid contents were measured as mg quercetin equivalent $(\mathrm{QE}) \mathrm{g}^{-1}$ extract and varied between 17.30-41.40 $\mathrm{mg} \mathrm{QE} \mathrm{g}^{-1}$ extract. The methanol extracts of HS and HC exhibited maximum radical scavenging activities for DPPH radical (79.76\% and $75.69 \%$, respectively) and ABTS (54.74\% and $55.13 \%$, respectively). Thus, Haplophyllum suaveolens varieties exhibited strong radical scavenging activity and methanol extracts were found to be more effective than ethanol extracts in both varieties. In this study, it has been determined that Haplophyllum suaveolens varieties have strong radical scavenging activity and maybe good natural antioxidant sources for medical and commercial use.
\end{abstract}

Keywords: Antioxidant activity, flavonoid, Haplophyllum L., phenolic 


\section{Giriş}

Rutaceae familyasına ait, çok yıllık otsu ve hoş kokulu bitkiler olan Haplophyllum, dünyada yaklaşı 68 tür içeren bir cinstir. Akdeniz Bölgesi'nden Doğu Sibirya'ya kadar geniş bir coğrafi dağılımı olan Haplophyllum cinsi, batıda Fas ve İspanya'dan doğuda Çin'e, kuzeyde Romanya'dan güneyde Somali'ye kadar yayılmaktadır. Fakat en fazla tür çeşitliliği Türkiye ve İran florasında bulunmaktadır (Townsend, 1986).

Townsend (1967)'e göre Türkiye'de Haplophyllum cinsi, 14 tür'e ait 17 takson (\% 52 endemizm) ile temsil edilmektedir. Ancak, Tugay ve Ulukuş (2017) Türkiye florasında Haplophyllum sahinii isimli türü yeni teşhis etmişler ve Türkiye'de 10'u endemik olan 18 Haplophyllum takson olduğunu ifade etmişlerdir. Bu türün teşhisi ile \% 55 endemizm oranına yükselen Haplophyllum cinsi, Türkiye için önemli bir gen merkezine sahiptir. Bu cins temel olarak kayalık tepelerde, bozkırlarda, yamaçlarda veya kumlu topraklarda yetişmektedir (Townsend, 1986).

Rutaceae familyasının üyeleri odun, yemek, kozmetik ve tıbbi kullanımlar dahil olmak üzere büyük bir ekonomik öneme sahiptir (Debouba ve ark., 2014). Geleneksel tıpta birçok ülkede farklı hastalıkların tedavisinde kullanılan Haplophyllum türleri, Suudi Arabistan'da sitma, romatoid artrit ve jinekolojik hastalıkların tedavisinde kullanılmaktadır (Al-Yahya ve ark., 1992). Herba kısminın infüzyon örnekleri ise jinekolojik problemleri ve romatoid artritin yanı sira kabılık ve ishal gibi sindirim problemlerini tedavi etmede (Mossa ve ark., 1987; Said ve ark., 2002), yaprakları Umman'da cilt enfeksiyonlarının tedavisinde (Mossa ve ark., 2012) kullanılmaktadır. Bitkinin herba kısmından Sudan'da alerjik rinit ve jinekolojik hastalıklar, astım ve solunum güçlüğü tedavisinde antispazmodik olarak yararlanılmaktadır (Mohamed ve ark., 1996). Ayrıca türlerin birçoğu antimikrobiyal (Bergheul ve ark., 2017), antioksidan (Hamdi ve ark., 2017), antiviral, anti-enflamatuar (Schinella ve ark., 2008), sitma (Ulubelen ve Öztürk, 2008), anti ülser (Awaad ve Alothman, 2018) dahil olmak üzere önemli biyolojik aktiviteler göstermektedir.

Birçok araştırmacı önceki fitokimyasal araştırmalarda, çeşitli Haplophyllum L. türlerinin flavonoidler, flavonoller, kumarinler, alkaloidler ve önemli lignan gibi sekonder metabolitleri içerdiğini bildirmiştir (Ulubelen ve Öztürk, 2008; Prieto, 2012). Bu fitokimyasal çalışmalar, Haplophyllum türlerinin çeşitli biyokimyasal bileşikler sergilediğini göstermektedir. Aslında, literatürlere göre, bu sekonder metabolitlerin biyosentezi ve dolayısıyla onların biyolojik aktiviteleri hem çevresel faktörler (toprak, 1şık yoğunluğu ve iklim şartları) (Russo ve ark., 2013) gibi dış faktörlerden hem de bitkinin biyotip ve kemotip olması (Duarte ve ark., 2010), fizyolojik ve genetik yönleri ( $\mathrm{Li}$ ve ark., 2015) gibi birçok iç faktörden etkilenir. Hatta, sekonder metabolit ve biyolojik aktivite varyasyonu için bitkinin fenolojik aşamaları en dış etken faktörler arasında yer aldığı bildirilmiştir (Mirjalili ve ark., 2006; Hosni ve ark., 2011).

$\mathrm{Bu}$ nedenle, kimyasal sinifların ya da spesifik bir bileşiğin ilgili endüstrilerde (örneğin; gıdalarda, ilaçlarda ve kozmetik preparatlarda) kullanımı için bitkilerden izole edilmesi, izolasyon stratejisinin daha az zahmetli olması ve biyolojik aktiviteler bakımından seçilen bileşiklerin daha iyi kalitede ve miktarlarda olması gerekmektedir. Bu özellikler belirlenirken dış ve iç faktörlere bağlı olarak dikkatli bir şekilde gerçekleştirilmelidir. Buna ilaveten, en son aşamada, fenolojik döngü sırasındaki seçilen kimyasalların ya da spesifik bir bileşiğin varyasyon bilgisi, optimum hasat zamanının belirlenmesini sağlamaktadır. Ayrıca bir bitkide bulunan kimyasalların ya da bileşiğin bitkiden izolasyonu/ekstraksiyonu ve kullanılan organik çözücü farklılığı, o bileşiğin iyi kalite ve miktarda alınmasını etkilemektedir. Bundan dolayı, bu çalışmanın amacı biri Türkiye endemiği olan iki Haplophyllum suaveolens varyetelerine ait etanol ve metanol ekstraktların antioksidan aktivite seviyeleri ile toplam biyoaktif içeriklerinin tespit etmek, analizler sonucu varyete ve çözücü farkını ortaya koymaktır.

\section{Materyal ve Yöntem}

\subsection{Materyal}

Haplophyllum suaveolens (DC.) G.Don var. suaveolens (HS) ve endemik Haplophyllum suaveolens var. cilicicum (Boiss.) C.C.Townsend (HC) tam çiçeklenme döneminde, her bir takson için toplam 40 adet bitkiye karşılık gelen bitki sürgünleri toplanmıştır (Şekil 1). Toplama işlemi tamamen rastgele tasarıma göre yapılmıştır. Taksonlar Selçuk Üniversitesi, Fen Fakültesi, herbaryumda Tablo 1'de verildiği gibi teşhis edilerek herbaryum numarası ile numaralandırılmış ve toplama yerleri kaydedilmiştir.

\subsection{Ekstraksiyon}

Haplophyllum L.'un kurutulan toprak üstü kısımları blender yardımı ile öğütülmüş, ögütülen numuneler yaklaşık $4 \mathrm{~g}$ ağırlığında tartılmış, 24 saat boyunca $40{ }^{\circ} \mathrm{C}$ 'de $(1 / 10)$ metanol ve etanol içerisinde bekletilmiştir. Elde edilen çözeltiler Whatman kâğıdı ile filtrelenmiş ve çözücüler evaporatör yardımı ile uzaklaştırılmıştır. 
Ekstrakların verimleri hesaplandıktan sonra ekstraklar etanol ve metanolde tekrar çözülmüştür. Her bir deneme 3 tekerrürlü yapılmış olup, numuneler analiz sonuna kadar $+4{ }^{\circ} \mathrm{C}$ 'de ağz1 parafinli şekilde bekletilmiştir.

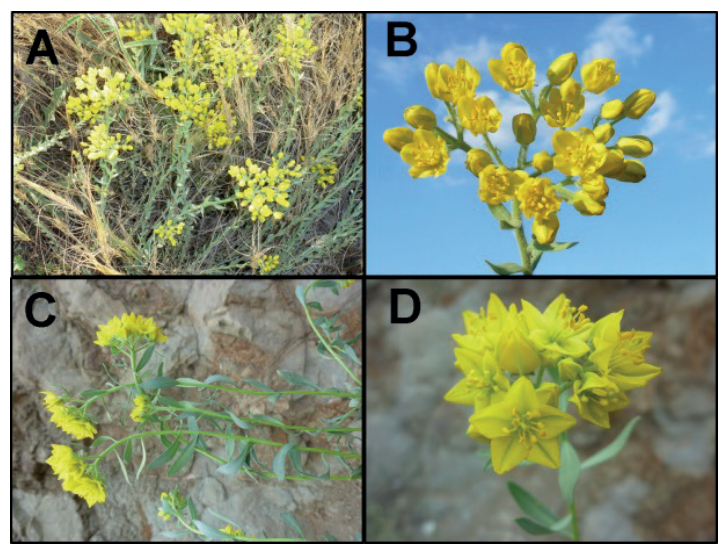

Şekil 1. Haplophyllum suaveolens (DC.) G.Don var. suaveolens (A\&B) ve endemik Haplophyllum suaveolens var. cilicicum (Boiss.) C.C.Townsend (C\&D) doğal ortamda görünüşü

\subsection{Toplam biyoaktif içerikler}

\subsubsection{Toplam fenolik içerik}

Numunelerin toplam fenolik içeriği FolinCiocalteu reaktif metoduna göre modifiye edilerek belirlenmiştir (Singleton ve ark., 1999). Her numune $(200 \mu \mathrm{L})$ distile su $(9 \mathrm{~mL})$ ile seyreltildikten sonra Folin-Ciocalteu reaktifi (200 $\mu \mathrm{L})$ ile karıştırılmış, 3 dakika boyunca kuvvetlice çalkalanmış ve en son $\mathrm{Na}_{2} \mathrm{CO}_{3}(\%$ 20) çözeltisi $(600$ $\mathrm{uL})$ ilave edilmiştir. Daha sonra numuneler karanlıkta 2 saat oda sıcaklığında inkübe edilmiş ve absorbans ölçümleri 760 nm'de okutulmuştur. Her bir deneme 4 tekerrürlü olarak yürütülmüştür. Örneklerin toplam fenolik içerikleri gallik asit grafiğine göre mg gallik asit eşdeğeri (GAE) $\mathrm{g}^{-1}$ ekstrakt olarak ifade edilmiştir.

\subsubsection{Toplam flavonoid içerik}

Numunelerin toplam flavonoid içerikleri Arvouet-Grand ve ark. (1994)'na göre modifiye edilerek yapılmıştır. Her numune $(200 \mu \mathrm{L})$ ayrı tüplerde $100 \mu \mathrm{L}$ alüminyum nitrat (\% 10) ve $100 \mu \mathrm{L}$ potasyum asetat $(1 \mathrm{M})$ ile karıştırılmıştır. Toplam çözelti hacmi etanol ile $4 \mathrm{~mL}$ 'ye ayarlanmıştır. Daha sonra, numuneler oda sıcaklığında 40 dakika karanlıkta inkübe edilmiş ve absorbans ölçümleri 417 nm'de okunmuştur. Her bir deneme 4 tekerrürlü olarak kurulmuştur. Örneklerin toplam flavonoid içerikleri kuersetin grafiğine göre mg kuersetin eşdeğeri (KE) $\mathrm{g}^{-1}$ ekstrakt olarak ifade edilmiştir.

\subsection{Radikal kovucu aktiviteleri}

\subsubsection{2,2-difenil-1-pikrilhidrazil (DPPH)}

Örneklerin DPPH radikal kovucu aktiviteleri Gezer ve ark. (2006)'na göre analiz edilmiştir. Her numuneden iki yüz mikrolitre $\left(500 \mu \mathrm{g} \mathrm{mL}^{-1}\right)$ alınmış ve $3.2 \mathrm{~mL}$ DPPH çözeltisine (\% 0.004 metanol) ilave edilmiştir. Daha sonra, numuneler oda sıcaklığında 30 dakika karanlıkta inkübe edilmiş ve absorbans ölçümleri 517 nm'de okunmuştur. Her bir deneme 3 tekerrürlü (her 2 uygulama 1 tekerrür) olarak kurulmuştur.

\subsubsection{2,2'-azinobis (3-etil-bezotiazolin 6 sulfonat) (ABTS)}

Örneklerin ABTS radikal kovucu aktiviteleri Miller ve ark. (1993) ve Re ve ark. (1999)'na göre modifiye edilerek analiz edilmiştir. ABTS çözeltisi $7.8 \mathrm{~mL}$ distile saf su içerisinde $6.6 \mathrm{mg}$ potasyum persülfat ile $30 \mathrm{mg}$ ABTS reaksiyonu ile elde edilmiş ve karışım oda sıcaklığında karanlıkta 12-16 saat bekletilmiştir. Daha sonra ABTS çözeltisi metanol ile $734 \mathrm{~nm}$ 'de $0.700 \pm 0.020$ absorbansa ayarlanmıştır. Her bir örnekten $100 \mu \mathrm{L}$ (200 $\left.\mu \mathrm{g} \mathrm{mL}^{-1}\right)$ ABTS çözeltisine $(2.9 \mathrm{~mL})$ eklenmiş ve karıştırılmıştır. Daha sonra numuneler oda sıcaklığında 30 dakika karanlıkta inkübe edilmiş ve absorbans ölçümleri 734 nm'de okutulmuştur.

\section{5. İstatistiki analizler}

Her iki varyeteye ait etanol ve metanol ekstraktlarının ekstrakt verimleri, toplam biyoaktif içerikleri ve radikal kovucu aktivitelerin verilerine, Düzgüneş ve ark. (1983) tarafından bildirildiği şekilde varyans analizi uygulanmış ve ortalamalar arasındaki farklılıklar Duncan testi ile kontrol edilmiştir. Yüzde ile ifade edilen değerler istatistiki analiz öncesi açı değerlerine dönüştürülerek (Snedecor ve Cochran 1967) varyans ve Duncan analizine tabi tutulmuştur.

Tablo 1. Haplophyllum suaveolens (DC.) G.Don var. suaveolens (HS) ve endemik Haplophyllum suaveolens var. cilicicum (Boiss.) C.C.Townsend (HC) varyetelerinin toplama zamanı ve lokasyonları

\begin{tabular}{cccccc}
\hline Kısaltılmış ismi & Tehlike kategorileri & Rakım $(\mathrm{m})$ & Toplama zaman1 & Lokasyon $^{2}$ & Herbaryum no \\
\hline HS & - & 1200 & 17.07 .2014 & $\begin{array}{l}\text { C3 }^{3} \text { Antalya; Elmal1- } \\
\text { Korkuteli arası }\end{array}$ & OT-9633-DU \\
\hline HC & NT & 1040 & 15.07 .2012 & $\begin{array}{l}\text { C5 Niğge; Ulukışla, } \\
\text { Alihoca Köyü }\end{array}$ & OT-7536-DU \\
\hline
\end{tabular}

${ }^{1}:$ NT, Tehdit altına girmeye yakın; -, endemik değil (Anonymous, 2001), ${ }^{2}$ : Türkiye, 3: Türkiye grid haritasına ait kareler 


\section{Bulgular ve Tartışma}

Bu çalışmada, HS ve endemik HC varyetelerinden elde edilen metanol ve etanol ekstraktların, toplam biyoaktif bileşenler ve radikal kovucu aktiviteleri araştırılmıştır. Her iki varyetenin etanol ve metanol çözücülerine ait ekstrakt verimleri Şekil 2'de verilmiştir.

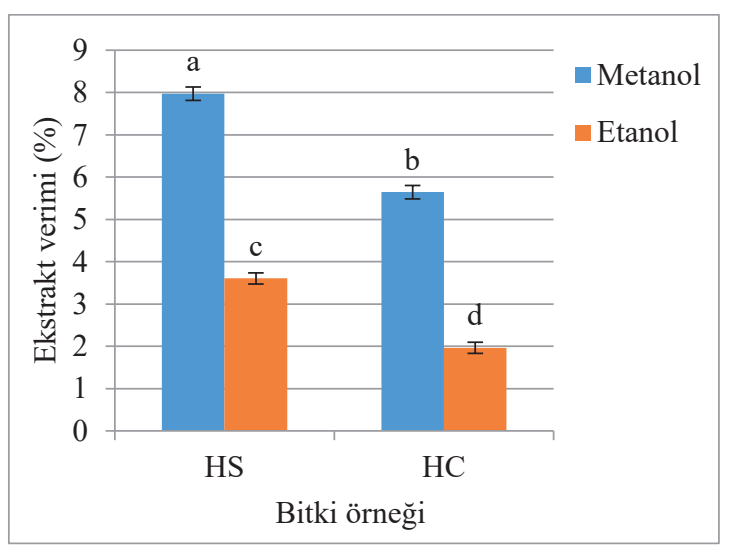

Şekil 2. Haplophyllum suaveolens (DC.) G. Don var. suaveolens (HS) ve endemik Haplophyllum suaveolens var. cilicicum (Boiss.) C.C.Townsend (HC) taksonların etanol ve metanol ekstrakt verimi

Ekstraksiyon, fitokimyasalların bitki materyalinden geri kazanılması ve izole edilmesi için ana adımdır. Ekstraksiyon etkinliği, fitokimyasalların kimyasal yapısından, kullanılan ekstraksiyon yönteminden, örnek partikül boyutundan, kullanılan çözücünün yanı sıra çözücü tarafından çözünmeyen maddelerin varlığından etkilenmektedir (Stalikas, 2007). Ekstraksiyon verimi çözücünün polaritesine, pH'sına, sıcaklığa, ekstraksiyon süresine, basinca, ekstraksiyon yöntemi ve örneğin kompozisyonuna bağlıdır (Lu ve ark., 2011; Prasad ve ark., 2012; Erşan ve ark., 2018). Aynı ekstrasksiyon yöntemi, süresi ve sıcaklığında çözücü ve fitokimyasal bileşimlerin ekstraksiyon verimi için en önemli parametreler olarak bilinir.

Bu çalışmada, her iki varyete için de en yüksek ekstrakt verimi metanol çözücüsünden elde edilmiş olup, HS varyetesinin ekstrakt verimi istastiki olarak en yüksek verime $(\% 7.97, \mathrm{p}<0.05)$ sahip olduğu tespit edilmiştir. HC varyetesi HS varyetisine göre daha düşük ekstrakt verimi sergilemiştir. Hatta, HC varyetesinin etanol ekstraktı istatistiki olarak en düşük ekstrakt verimi (\% 1.96) göstermiştir (Şekil 2). Bu varyetelerin ekstrakt verimleri için HS varyetenin ve metanol çözücüsünün daha etkili olduğu saptanmıştır.

Pavlović ve ark. (2018) Haplophyllum suaveolens (DC.) G. Don taksonunun etanol ve metanol ekstrakt verimini sirasiyla \% 11.3 ve
\% 14.9 olarak belirlemişlerdir. Bu çalışma ile benzer olarak metanol ekstrakt veriminin daha fazla olduğu gözlenmiştir. Birçok araştırmacı da metanol çözücüsünün etanol çözücüsünden daha yüksek ekstrakt verimi elde ettiklerini bildirmişlerdir (Sun ve Ho, 2005; Do ve ark., 2014). Dai ve Mumper (2010) da, metanol çözücüsünün düşük moleküler ağırlıklı polifenollerin ekstraksiyonunda genellikle daha etkili olduğunu bildirmişlerdir. Önceki araştırmalarda, Haplophyllum türlerinin hava kısımlarına ait metanol ekstrakt verimlerinin; Schinella ve ark. (2002) Haplophyllum hispanicum Spach. türü için \% 8.7, Parhoodeh ve ark. (2012) Haplophyllum laeviusculum \% 3.26, Debouba ve ark. (2014) Haplophyllum tuberculatum \% 1.94, Zengin ve ark. (2014) Haplophyllum myrtifolium Boiss. türü için \% 18.83, Yamauchi ve ark. (2016) Haplophyllum tuberculatum Forsk. \% 17.2 olduğunu bildirmişlerdir. Ekstrakt verimlerindeki varyasyonun tür, lokasyon, hasat dönemi, ekstraksiyon uygulamalarındaki farklılıklardan kaynaklandığı düşünülmektedir.

HS ve endemik HC metanol ve etanol ekstraktların toplam biyoaktif bileşenleri olarak toplam fenolik ve flavonoid içerikleri incelenmiştir. Her iki varyetenin toplam fenolik içerikleri (TP) Şekil 3'te belirtildiği gibi gallik asit standart grafik eğrisine $\left(y=0.0089 x-0.0003 ; R^{2}=0.999\right)$ göre hesaplanmış ve mg GAE $\mathrm{g}^{-1}$ ekstrakt olarak ifade edilmiştir. En yüksek TP içerik 44.16 mg GAE g-1 ekstrakt ile HC metanol ekstraktında, en düşük ise $39.54 \mathrm{mg}$ GAE $\mathrm{g}^{-1}$ ekstrakt ile $\mathrm{HC}$ etanol ekstraktında kaydedilmiş ve istatiksel olarak farklı grupta yer almıştır $(\mathrm{p}<0.05)$. Her iki varyete ayrı olarak değerlendirildiği zaman, en yüksek TP içerik metanol ekstraktlarında bulunmuştur (Şekil 3).

Her iki varyetenin toplam flavonoid içerikleri (TF) Şekil 4'te belirtildiği gibi kuersetin standart grafik eğrisine $\left(\mathrm{y}=0.0122 \mathrm{x}+0.065 ; \mathrm{R}^{2}=0.9997\right)$ göre hesaplanmış ve mg KE g-1 ekstrakt olarak ifade edilmiştir. En yüksek TF içerik $41.40 \mathrm{mg} \mathrm{KE} \mathrm{g}^{-1}$ ekstrakt ile HC metanol ekstraktında, en düşük içerik ise $17.30 \mathrm{mg} \mathrm{KE} \mathrm{g}^{-1}$ ekstrakt ile $\mathrm{HC}$ etanol ekstraktında gözlenmiş ve istatiksel olarak $\mathrm{p}<0.05$ seviyesinde öenmli olduğu tespit edilmiştir (Şekil 4). HS varyetesinin metanol ve etanol ekstraklarındaki TF içeriklerinin istatiksel olarak aynı grupta yer aldığı ve yüksek miktarlarda olduğu saptanmıştır (sırasıyla, 40.82 ve $40.89 \mathrm{mg} \mathrm{KE} \mathrm{g}^{-1}$ ekstrakt)

Her iki varyetede TF içeriğini TP içeriğinden düşük fakat yüksek oranda olduğu tespit edilmiştir. Debouba ve ark. (2014) Haplophyllum tuberculatum taksonunun metanol ekstraktının TP içeriği $184.54 \mathrm{mg} \mathrm{GAE} \mathrm{g}^{-1}$ ekstrakt ve TF içeriği 


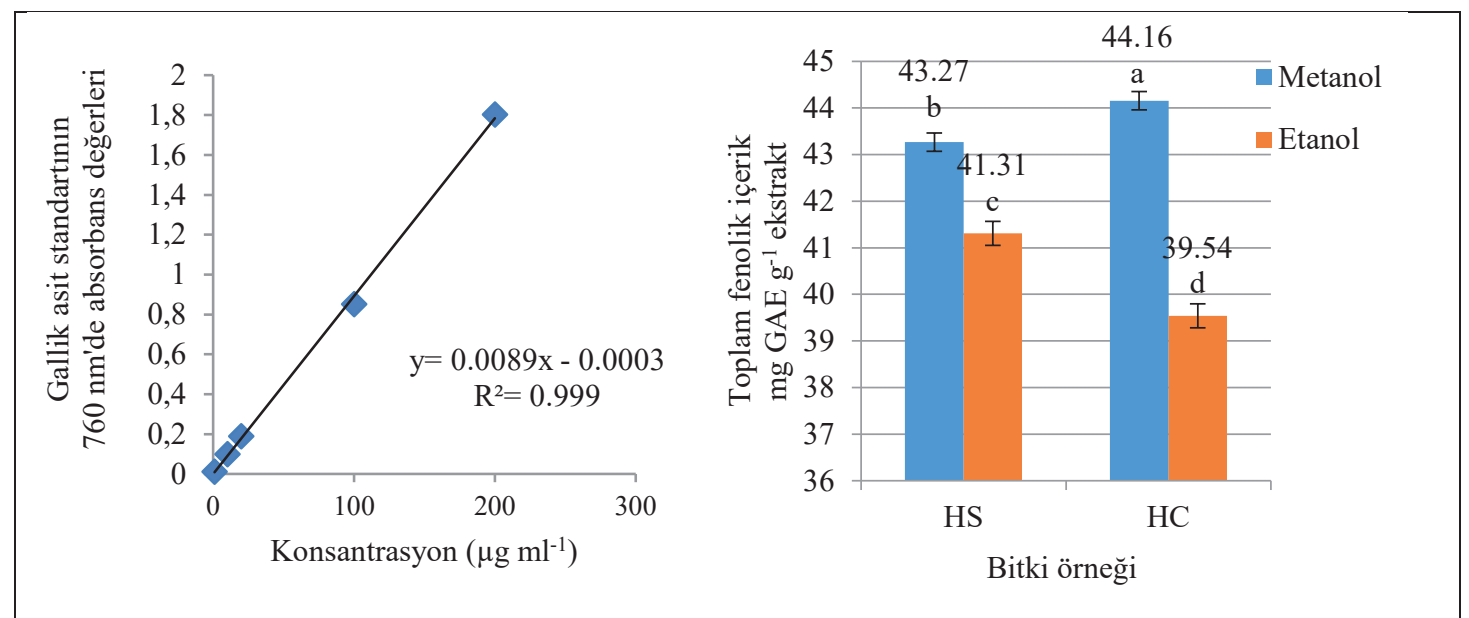

Şekil 3. Haplophyllum suaveolens (DC.) G. Don var. suaveolens (HS) ve endemik Haplophyllum suaveolens var. cilicicum (Boiss.) C.C.Townsend (HC) taksonların etanol ve metanol ekstraktlarının toplam fenolik içerikleri (TP) ve gallik asit standart grafik eğrisi

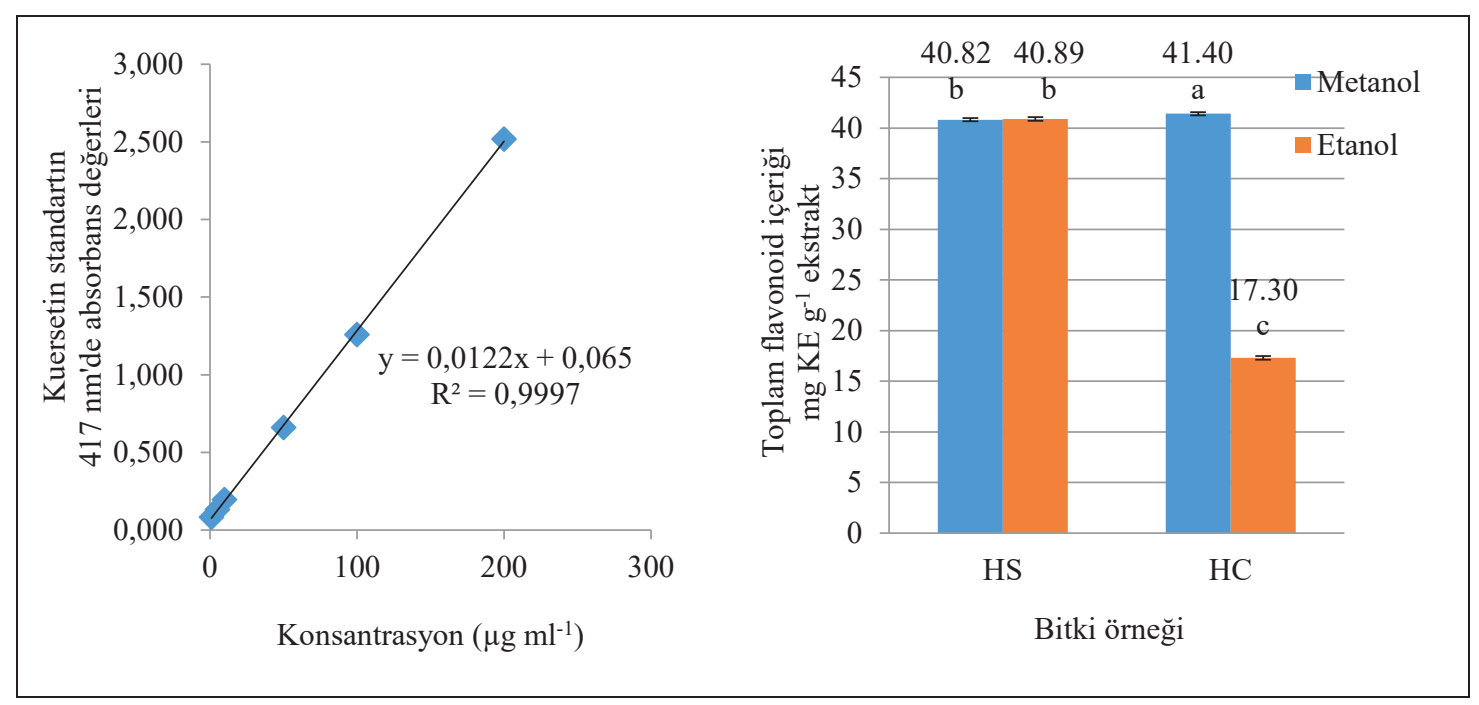

Şekil 4. Haplophyllum suaveolens (DC.) G. Don var. suaveolens (HS) ve endemik Haplophyllum suaveolens var. cilicicum (Boiss.) C.C.Townsend (HC) taksonların etanol ve metanol ekstraktlarının toplam flavonoid içerikleri (TF) ve kuersetin standart grafik eğrisi

24.88 mg KE g-1 ekstrakt, kloroform ve hekzan ekstraktların ise TP içeriğin yaklaşık yarısının TF içerik olduğunu tespit etmişlerdir. Pavlović ve ark. (2018) HS taksonunun metanol ve etanol ekstraktlarının TF içeriğini sırasıyla 13.95 ve 15.88 $\mathrm{mg}$ rutin $\mathrm{g}^{-1}$ ekstrakt olarak ifade etmişlerdir. Zengin ve ark. (2014) Haplophyllum myrtifolium türünün metanol ve su ekstraklarının TF içeriğinin TP içeriğinden daha fazla gözlemişlerdir.

HS ve endemik HC metanol ve etanol ekstraktların radikal kovucu aktiviteleri DPPH ve ABTS radikalleri ile \% inhibisyon olarak belirlenmiştir. Sonuçlara göre, Şekil 5 incelendiğinde, HC ve HS taksonlarının yüksek oranda radikal kovucu aktivitelerinin olduğu saptanmıștır. HC ve HS ekstraktlarının ABTS radikal kovucu aktivitelerinin $\% 44.21$ ile \% 55.13, DPPH radikal kovucu aktivitelerinin ise \% 52.6 ile \% 79.76 arasında değiştiği kaydedilmiştir (Şekil 5).

En yüksek antioksidan aktivite her iki varyete içinde en yüksek toplam fenolik ve flavonoid içeriklere sahip olan metanol ekstraktlarında gözlenmiştir. Etanol ekstraktlarında ise daha düşük antioksidan aktivite tespit edilmiştir.

Fenolikler, özellikle flavonoidler doğrudan antioksidan aktivite ile ilişkilidir (Li ve ark., 2012). Flavonoidler güçlü indirgeyici özelliğe sahip olduklarından yüksek antioksidan aktivite sergileme potansiyeline sahiptir (Koley ve ark., 2016). Bu çalışmada da benzer sonuçlar elde 
edilmiş, fakat varyeteler arasında farklılıklar da tespit edilmiştir. Bu farklılı̆̆ın, varyetelerde biyoaktif bileşik çeşitliliği ve miktarındaki varyasyonla ilişkili olabileceği düşünülmektedir.

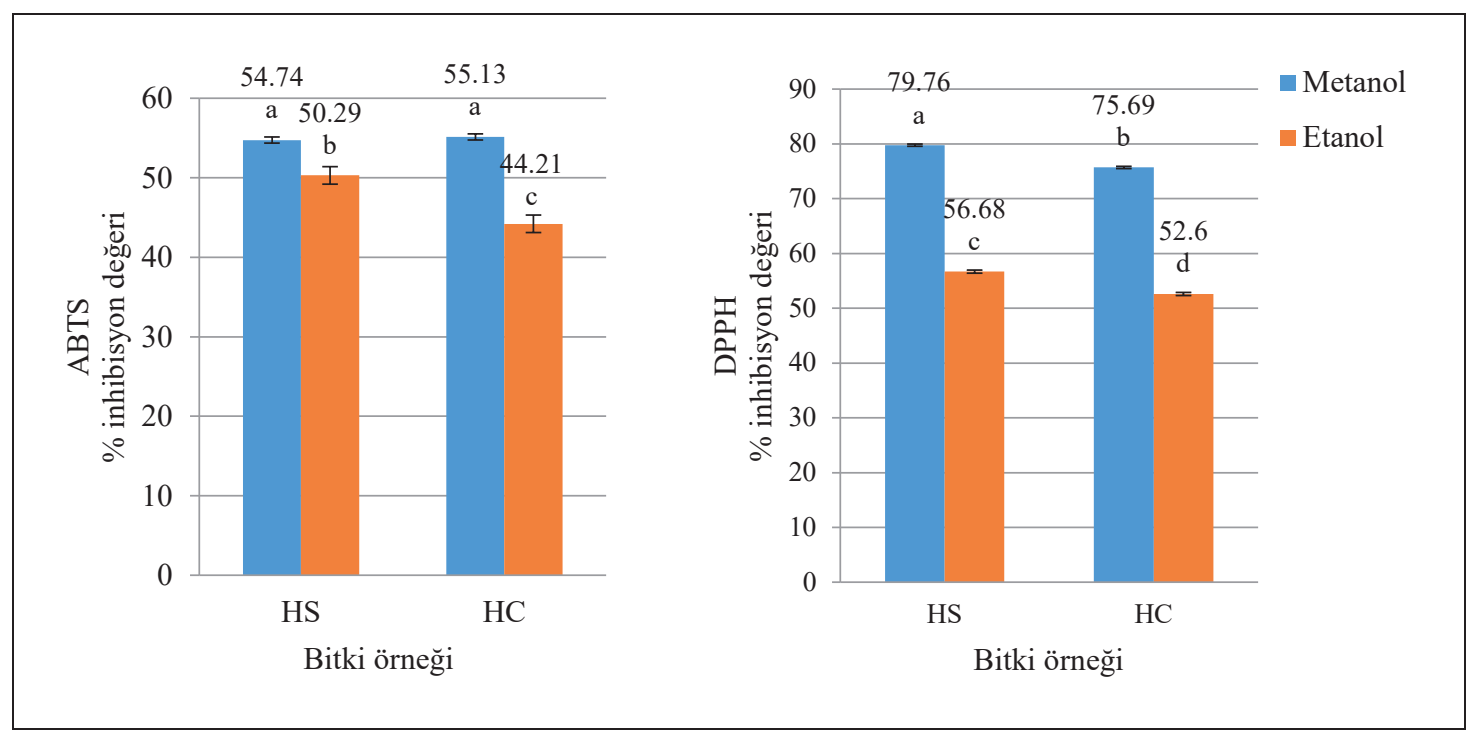

Şekil 5. Haplophyllum suaveolens (DC.) G. Don var. suaveolens (HS) ve endemik Haplophyllum suaveolens var. cilicicum (Boiss.) C.C.Townsend (HC) taksonların etanol ve metanol ekstraktlarının ABTS ve DPPH radikal kovucu aktiviteleri

Pavlović ve ark. (2018) HS taksonunun metanol ve etanol ektraktlarının radikal kovucu aktivitelerinin birbirine yakın, fakat metanol ekstraktın etanol ekstraktına göre daha aktif olduğunu tespit etmişlerdir. Zengin ve ark. (2014) Haplophyllum myrtifolium metanol ekstraktları diğer çözücü ekstraklarına göre yüksek DPPH radikal kovucu aktivite, etil asetat ekstraktına göre de düşük ABTS radikal kovucu aktivite sergilediğini bildirmiştir. ABTS ve DPPH radikalleri ekstraktların çözücü farkına göre farklılık göstermesi, ekstraktlarda çözünen bileşiklerin çeşitliliğine ve etki faktörüne bağlıdır. $\mathrm{Bu}$ iki radikalin etki faktörü, ABTS için elektron oksidanları (Tirzitis ve Bartosz, 2010), DPPH için ise donör bileşiklerinden elektron veya hidrojen radikalleri tarafından indirgenmesi ile ilişkilidir (Chen ve ark., 2013).

Sonuç olarak, her iki varyete için toplam biyoaktif madde içeriği ve antioksidan aktivitesi yönünden çözücüler arasından metanol ekstraktların daha etkili olduğu, varyeteler arasında ise $\mathrm{HC}$ taksonunun metanol ekstraktları daha yüksek biyoaktif madde içerdiği belirlenmiştir. Fakat her iki radikal kovucu aktivitede HS taksonunun metanol ekstrakları istatiksel olarak en yüksek grupta yer almıştır.

\section{Sonuçlar}

$\mathrm{Bu}$ çalışma, biri Türkiye endemiği olan iki adet Haplophyllum suaveolen varyetelerinin güçlü radikal kovucu aktiviteye sahip olduğunu, tıbbi ve ticari kullanım için iyi bir doğal antioksidan kaynakları olabileceğini göstermiştir. Gelecekte, bu araştırma sonucunda göreceli olarak yüksek antioksidan aktiviteye sahip olan ve potansiyel doğal antioksidan bileşik kaynakları sağlayabilen taksonun ekstraklarından aktif bileşenlerin tanımlanması ve karakterizasyonu gerçekleştirilebilinir. Bu anlamda, özellikle yüksek antioksidan aktiviteye ve düşük fenolik içeriğe sahip endemik Haplophyllum suaveolens var. cilicicum (Boiss.) C.C.Townsend taksonun ekstraktlarına odaklanabilir. $\mathrm{Bu}$ potansiyel taksonun mümkün olduğunca çok sayıda antioksidanın geri kazanılması için uygun bir ekstraksiyon prosedürü geliştirilebilir. Ayrıca gıda açısından güvenlik, yenilebilirlik ve in vivo etkinlik çalışmaları da yapılabilir.

\section{Teşekkür}

Bu çalıșma; Selçuk Üniversitesi, Bilimsel Araştırma Projeleri Koordinatörlüğü tarafından “13201023” No'lu proje ile desteklenmiştir. 


\section{Kaynaklar}

Al-Yahya, M.A., Al-Rehaily, A.J., Ahmad, M.S., AlSaid, M.S., El-Feraly, F.S., Hufford, C.D., 1992. New alkaloids from Haplophyllum tuberculatum. Journal of Natural Products, 55(7): 899-903.

Anonymous, 2001. IUCN Red List Categories: Version 3.1. Prepared by the IUCN Species Survial Commission. IUCN, Gland Switzerland and Cambridge, UK.

Arvouet-Grand, A., Vennat, B., Pourrat, A., Legret, P., 1994. Standardisation d'un extrait de propolis et identification des principaux constituants. Journal de Pharmacie de Belgique, 49: 462-468.

Awaad, A.S., Alothman, E.A.A., 2018. Antiulcer and anti-ulcerative colitis activities of Haplophyllum tuberculatum (Forsskal). International Journal of Pharmacology, 14(1): 31-38.

Bergheul, S., Berkani, A., Saiah F., Djibaoui, R., 2017. Chemical composition and antifungal activity of essential oils of Haplophyllum tuberculatum (Forssk.) A. Juss. from South Algerian. International Journal Bioscience, 10(5): 97-105.

Chen, Z., Bertin, R., Froldi, G., 2013. EC 50 estimation of antioxidant activity in DPPH assay using several statistical programs. Food Chemistry, 138(1): 414420.

Dai, J., Mumper, R.J., 2010. Plant phenolics: extraction, analysis and their antioxidant and anticancer properties. Molecules, 15(10): 7313-7352.

Debouba, M., Khemakhem, B., Zouari, S., Meskine, A., Gouia, H., 2014. Chemical and biological activities of Haplophyllum tuberculatum organic extracts and essential oil. Journal of Essential Oil Bearing Plants, 17(5): 787-796.

Do, Q.D., Angkawijaya, A.E., Tran-Nguyen, P.L., Huynh, L.H., Soetaredjo, F.E., Ismadji, S., Ju, Y., 2014. Effect of extraction solvent on total phenol content, total flavonoid content, and antioxidant activity of Limnophila aromatica. Journal of Food and Drug Analysis, 22(3): 296-302.

Duarte, A.R., Naves, R.R., Santos, S.C., Seraphinand, J.C., Ferri, P.H., 2010. Genetic and environmental influence on essential oil composition of Eugenia dysenterica. Journal Brazilian Chemical Social, 21(8): 1459-1467.

Düzgüneş, O., Kesici, T., Gürbüz, F., 1983. İstatistik Metotlar1 1. Ankara Üniversitesi Ziraat Fakültesi Yayıncılı̆̆ı, No: 862, Ankara.

Erşan, S., Güçlü Üstündağ, Ö., Carlea, R., Schweiggert, R.M., 2018. Subcritical water extraction of phenolic and antioxidant constituents from pistachio (Pistacia vera L.) hulls. Food Chemistry, 253(1): 46-54.

Gezer, K., Duru, M.E., Kıvrak, I., Türkoğlu, A., Mercan, N., Türkoğlu, H., Gülcan, S., 2006. Free-radical scavenging capacity and antimicrobial activity of wild edible mushroom of Turkey. African journal of Biyotechnology, 5(20): 1924-1928.

Hamdi, A., Majouli, K., Flamini, G., Marzouk, B., Marzouk, Z.V., Heyden, Y., 2017. Antioxidant and anticandidal activities of the Tunisian Haplophyllum tuberculatum (Forssk.) A. Juss. essential oils. South African Journal of Botany, 112: 210-214.

Hosni, K., Msaada, K., Taârit, B.M., Marzouk, B., 2011. Phenological variations of secondary metabolites from Hypericum triquetrifolium Turra. Biochemical Systematics and Ecology, 39(1): 43-50.

Koley, T.K., Kaur, C., Nagal, S., Walia, S., Jaggi, S., Sarika, 2016. Antioxidant activity and phenolic content in genotypes of Indian jujube (Zizyphus mauritiana Lamk.). Arabian Journal of Chemistry, 9(2): 1044-1052.

Li, B., Zhang, C., Peng, L., Liang, Z., Yan, X., Zhu, Y., Liu, Y., 2015. Comparison of essential oil composition and phenolic acid content of selected Salvia species measured by GC-MS and HPLC methods. Industrial Crops Products, 69: 329-334.

Li, X.C., Lin, J., Han, W.J., Mai, W.Q., Wang, L., Li, Q., Lin, M.F., Bai, M.S., Zhang, L.S., Chen, D.F., 2012. Antioxidant ability and mechanism of Rhizoma Atractylodes macrocephala. Molecules, 17(11): 13457-13472.

Lu, C.L., Li, Y.M., Fu, G.Q., Yang, L., Jiang, J.G., Zhu, L., Lin, F.L., Chen, J., Lin, Q.S., 2011. Extraction optimisation of daphnoretin from root bark of Wikstroemia indica (L.) C.A. and its anti-tumour activity tests. Food Chemistry, 124(4): 1500-1506.

Miller, N.J., Rice-Evans, C., Devies, M.J., Gopinathan, V., Milner, A., 1993. A novel method for measuring antioxidant capacity and its application to monitoring the antioxidant status in premature neonates. Clinical Science, 84: 407-412.

Mirjalili, M.H., Salehi, P., Sonboli, A., Vala, M.M., 200 6. Essential oil variation of Salvia officinalis aerial parts during its phenological cycle. Chemistry of Natural Compounds, 42(1): 19-23.

Mohamed, A.H., Ali, M.B., Bashir, A.K., Salih, A.M., 1996. Influence of Haplophyllum tuberculatum on the cardiovascular system. International Journal of Pharmacognosy, 34(3): 213-217.

Mossa, J.S., Al-Yahya, M.A., Al-Meshal, I.A., 1987. Medical Plants of Saudi Arabia. Vol. 1, Riyadh, King Saud University Libraries.

Mossa, J.S., Al-Yahya, M.A., Al-Meshal, I.A., 2012. Medical Plants of Saudi Arabia. King Saud University Libraries, Riyadh.

Parhoodeh, P., Rahmani, M., Hashim, N.M., Sukarı, M.A., Ee, G.C.L., 2012. Alkaloid constituents of Haplophyllum laeviusculum (Rutaceae). Sains Malaysiana, 41(1): 47-52.

Pavlović, D.R., Zlatković, B., Živanović, S., Kitić, D., Golubović, T., 2018. Serbian Rutaceae species: comparison of chemical profiles and radical scavenging activity. Biologica Nyssana, 9(1): 37-43.

Prasad, K.N., Kong, K.W., Ramanan, R.N., Azlan, A., Ismail, A., 2012. Determination and optimization of flavonoid and extract yield from brown mango using response surface methodology. Separation Science and Technology, 47(1): 73-80.

Prieto, J.M., 2012. In Book: Bioactive Compounds: Types, Biological Activities and Health Effects, 
Chapter: Haplophyllum A. Juss, A Rich Source of Bioactive Natural Principles, Publisher: Nova, 341380.

Re, R., Pellegrini, N., Proteggente, A., Pannala, A., Yang, M., Rice-Evans, C., 1999. Antioxidant activity applying an improved ABTS radical cation decolorization assay. Free Radical Biology \& Medicine, 26(9-10): 1231-1237.

Russo, A., Formisano, C., Rigano, D., Senatore, F., Delfine, S., Cardile, V., Rosselli, S., Bruno, M., 2013. Chemical composition and anticancer activity of essential oils of Mediterranean sage (Salvia officinalis L.) grown in different environmental conditions. Food Chemical Toxicogical, 55: 42-47.

Sağlam, H., Gözler, T., Gözler, B., 2003. A new prenylated arylnaphthalene lignan from Haplophyllum myrtifolium. Fitoterapia, 74(6): 564569.

Said, O., Khalil, K., Fulder, S., Azaizeh, H., 2002. Ethnopharmacological survey of medicinal herbs in Israel, the Golan Heights and the West Bank region. Journal of Ethnopharmacology, 83(3): 251-265.

Schinella, G.R., Tournier, H.A., Prieto, J.M., Ríos, J.L., Buschiazzo, H., Zaidenberg, A., 2002. Inhibition of Trypanosoma cruzi growth by medical plant extracts. Fitoterapia, 73(7-8): 569-575.

Schinella, G.R., Tournier, H.A, Zaidenberg, A., Prieto, J.M., 2008. On the preclinical anti-trypanosomal, anti-inflammatory and toxicological activities of Haplophyllum linifolium (L.) G. Don and its diphyllin derivatives. Boletín Latinoamericano y del Caribe de Plantas Medicinales y Aromáticas, 7(5): 225-228.

Singleton, V.L., Orthofer, R., Lamuela-Raventos, R.M., 1999. Analysis of total phenols and other oxidation substrates and antioxidants by means of FolinCiocalteu reagent. Methods in Enzymology, 299: 152178.
Snedecor, G.W., Cochran, W.G., 1967. Statistical Methods. The Iowa State University.

Stalikas, C.D., 2007. Extraction, separation, and detection methods for phenolic acids and flavonoids. Journal of Separation Science, 30(18): 3268-3295.

Sun, T., Ho C.H., 2005. Antioxidant activities of buckwheat extracts. Food Chemistry, 90(4): 743-749.

Tirzitis, G., Bartosz, G., 2010. Determination of antiradical and antioxidant activity: Basic principles and new insights. Acta Biochimica Polonica, 57(2): 139-142.

Townsend, C.C., 1967. Haplophyllum A. Juss. In: P.H. Davis (Ed), Flora of Turkey and The Aegean Islands, Edinburgh University Press. Edinburgh, Vol 2, pp. 496-506.

Townsend, C.C., 1986. Taxonomic revision of the genus Haplophyllum (Rutaceae). In: P.S. Green (Ed.), Hooker's icones plantarum, Kew Publishing, 40(1): 336

Tugay, O., Ulukuş, D., 2017. Haplophyllum sahinii (Rutaceae), a new species from Central Anatolia (Turkey). Phytotaxa, 29(3): 265-272.

Ulubelen, A., Öztürk, M,, 2008. Alkaloids, coumarins and lignans from Haplophyllum species. Records of Natural Products, 2(3): 54-69.

Yamauchi, K., Mitsunaga, T., Muddathir, A.M., 2016. Screening for melanogenesis-controlled agents using Sudanese medicinal plants and identification of active compounds in the methanol extract of Terminalia brownii bark. Journal of Wood Science, 62(3): 285293.

Zengin, G., Sarikurkcu, C., Aktumsek, A., Ceylan, R., Ceylan, O., 2014. A comprehensive study on phytochemical characterization of Haplophyllum myrtifolium Boiss. endemic to Turkey and its inhibitory potential against key enzymes involved in Alzheimer, skin diseases and type II diabetes. Industrial Crops and Products, 53: 244-251. 